\title{
Efficacy of Mind-Body Therapies for the Treatment of Urinary Incontinence in Women: A Systematic Review and Meta-Analysis of Randomized Controlled Trials
}

\author{
Kannan P*, Sy SL and Boghra S \\ Department of Rehabilitation Sciences, The Hong Kong \\ Polytechnic University, Hung Hom, Hong Kong \\ *Corresponding author: Priya Kannan, Department \\ of Rehabilitation Sciences, The Hong Kong Polytechnic \\ University, Hung Hom, Hong Kong
}

Received: April 05, 2021; Accepted: April 30, 2021; Published: May 06, 2021

\begin{abstract}
Introduction: The efficacy of mind-body therapies to manage urinary incontinence in women is outdated and inconclusive. This review aims to determine the efficacy of mind - body therapies for Stress Urinary Incontinence (SUI) in women.
\end{abstract}

Methods: The databases AMED, CINAHL, EMBASE, Medline, Physiotherapy Evidence Database (PEDro), PubMed, Scopus, and Web of Science, were searched from database inception until May 2020. Randomized controlled trials comparing mind-body therapies to control were included. The methodological quality and the quality of the evidence were evaluated using the Physiotherapy Evidence Database (PEDro) scale and the Grading of Recommendations, Assessment, Development, and Evaluation tool, respectively. The risk of bias was assessed using the Cochrane risk of bias tool.

Results: Six studies were included in the review. Pooled analysis of data from two studies of low to high methodological quality, low-grade evidence revealed a statistically significant decrease in the number of SUI episodes in the yoga group than in the control group (MD 0.83 [95\% Cl-1.64 to 0.02]; $p=0.04$ ). Pooled analysis of three methodologically low-quality, very low-grade studies revealed no significant difference between groups receiving Paula exercise and pelvic floor muscle training on grams of urine lost in the $1 \mathrm{~h}$ pad test (MD 0.15 [95\% $\mathrm{Cl}-1.15$ to 1.46$] \mathrm{p}=0.82$ ).

Conclusions: This review found hatha yoga poses intended to address the pelvic floor as beneficial for managing SUI in women. Yoga is a low-risk intervention and therefore it may be considered for clinical use. The effect of Paula exercise on SUI remains inconclusive.

Keywords: Physiotherapy Evidence Database (PEDro); Mind-body therapies; Urinary incontinence

\section{Introduction}

Mind-body interventions encompass a group of healing techniques and therapies designed to promote the mind's capacity to influence health [1]. Because mind-body therapies involve lowcost, self-care-based activities 1 and are associated with minimal sideeffects [2], they are popular in the West and preferred by women [3].

Mind-body therapies, excluding biofeedback, for urinary incontinence include yoga, Tai Chi, Pilates, Qigong, and Paula exercise. Several different mechanisms have been proposed for the effectiveness of these interventions on urinary incontinence. The combination of breathing, relaxation, and muscle control techniques of yoga are thought to contribute to the strengthening of the Pelvic Floor Muscles (PFMs) $[4,5]$. Pelvic floor lift that occurs during exhalation is believed to increase the strength and tone of the PFMs [4]. Yoga is reportedly beneficial or an effective adjunct for cardiorespiratory [6,7], musculoskeletal [8,9] and neurological conditions [10] and cancer-related symptoms [11], but its effectiveness for the treatment of UI is inconclusive [5].
Tai Chi is a Chinese martial art widely practiced because of its health benefits. A specific Tai Chi exercise called "the deer" that involves the contraction of the anal sphincter is recommended for the management of urinary incontinence [12]. According to traditional Chinese medicine theory, urinary incontinence is caused by a deficiency of "qi" (energy flow) of the kidneys, resulting in "bladder's failure" to control urination [13]. Qigong exercise is thought to improve kidney and bladder health by regulating qi [14]. A specific Qigong exercise called "kidney breathing" regulates qi to the kidneys and bladder, thus promoting the recovery of bladder function [14]. The efficacy of Tai Chi and Qigong to manage urinary incontinence is not known.

Pilates incorporates exercises that involve breathing and contraction of PFMs. The PFM co-contraction that occurs during Pilates exercises is thought to counteract increases in intra-abdominal pressure during exercise, preventing leakage and strengthening the PFMs $[12,15]$. However, the effectiveness of Pilates for improving UI is currently inconclusive [12]. The Paula exercise was developed in 1993. It is based on the theory that all the sphincters in the body work
Austin J Womens Health - Volume 8 Issue 2 - 2021

Submit your Manuscript | www.austinpublishing group.com

Kannan et al. (C) All rights are reserved
Citation: Kannan P, Sy SL and Boghra S. Efficacy of Mind-Body Therapies for the Treatment of Urinary Incontinence in Women: A Systematic Review and Meta-Analysis of Randomized Controlled Trials. Austin J Womens Health. 2021; 8(2): 1050. 
concomitantly and that contracting the circular muscles of the face including the eyes, mouth and nose can strengthen the PFMs $[16,17]$. The efficacy of Paula for managing urinary incontinence in women is inconclusive [12].

The efficacy of biofeedback alone and in conjunction with Pelvic Floor Muscle Training (PFMT) for the treatment of urinary incontinence in women is well documented in several systematic reviews [18-21]; therefore, this review did not include biofeedback The Cochrane group that evaluated the efficacy of yoga for urinary incontinence in women reported inconclusive results because a quantitative synthesis of data in a meta-analysis could not be performed due to the variability in control conditions in the included studies [5] One review evaluated the efficacy of alternative exercises including yoga, Pilates, Paula exercise and Tai Chi for urinary incontinence but the review was published more than a five years ago [12]. We did not find any reviews of the efficacy of Qigong for the treatment of urinary incontinence in women. The objective of this review was to determine the efficacy of mind-body (Pilates, yoga, Paula, Tai Chi and Qigong) therapies for managing urinary incontinence in women, given that previous reviews were published five years ago, either are inconclusive, or did not include a meta-analysis.

\section{Methods}

This systematic review was developed and reported following the preferred reporting items for systematic review and meta-analyses guidelines. An extensive electronic search of several databases, including AMED, CINAHL, EMBASE, Medline (EBSCO host), Physiotherapy Evidence Database (PEDro), PubMed, Scopus, and Web of Science, was conducted from database inception until May 2020 using the following search terms: urinary incontinence, mindbody therapies (Paula exercise, Qigong, Tai Chi, Pilates, and yoga) and randomized controlled trials (RCTs). Reference lists of relevant studies were hand-searched for any other potentially relevant articles. Supplementary Appendix 1 provides a detailed description of the search terms used. Two reviewers independently screened and selected the studies. Conflicts between the reviewers were discussed until a consensus was reached. A third reviewer was consulted for any unresolved conflict.

RCTs, pilot RCTs, randomized crossover trials presenting data before crossover, cluster trials or unpublished works (theses) that compared Paula exercise, Qigong, Tai Chi, Pilates or yoga with control (medical treatments, no treatment, sham, usual care, attention (non-specific exercises) or active treatment (e.g., PFM training)) for stress, urge, or mixed urinary incontinence in women were included. Studies that utilized at least one of the following outcomes to measure the effectiveness of interventions on urinary incontinence in women were included in the review: bladder diaries, $24 \mathrm{~h}$ or $1 \mathrm{~h}$ pad tests, selfor caregiver-reported complete or partial cure of continence, number of urge accidents, number of incontinence episodes, or women using urine pads. Conference abstracts with available full texts and studies published in English, Chinese and Cantonese were included in the review. Quasi-experimental designs, studies comparing active interventions, and studies using a combination of treatments as control arm were excluded.

Two independent reviewers did data extraction for each included study. First author, year of publication, mean age (and Standard Deviation (SD)) of participants, sample size per group, intervention and control and results ( $\mathrm{n}$ for dichotomous variables or mean and SD data for continuous variables) were extracted from each included study.

Methodological quality and the quality of evidence were assessed using the PEDro scale [22] and the Grading of Recommendations; Assessment, Development and Evaluation (GRADE) tool [23], respectively. Two independent reviewers assessed methodological quality, and the results were compared with the scores reported on the PEDro website (http://search.pedro.org.au/search). Discrepancies in scores between reviewers and scores reported on PEDro were discussed with a third reviewer. Studies scoring $\geq 6$ out of 10 were considered high quality, whereas those with a score of $\leq 5$ out of 10 were considered low quality [24].

The GRADEpro software (version 3.6.1, http://tech.cochrane. org/revman/other-resources/gradepro/download) was used in rating the quality of evidence. Following the GRADE system, studies were rated as "high," "moderate," "low", or "very low" [25]. Studies were rated across outcome measures based on the following factors: risk of bias (methodological flaws, such as lack of allocation concealment, assessor/therapist blinding, intention-to-treat analysis and inadequate follow up $>15 \%$ ) [26], indirectness of evidence [27], imprecision [28], the inconsistency of results across studies ( $>50 \%$ ) [29], and publication bias [30]. Studies were not down-graded for lack of participant blinding because of the nature of the intervention. Because studies with similar interventions were pooled together, studies were not downgraded for indirectness of evidence. A funnel plot was planned if more than ten studies were pooled in the metaanalysis for downgrading because of publication bias.

The risk of bias in the included studies was evaluated using the Cochrane risk of bias tool [31]. The following six domains were assessed for each included study: sequence generation, allocation concealment, blinding of participants, personnel and outcome assessors, incomplete outcome data, selective outcome reporting, and other sources of bias (validity of outcome measure, baseline comparability, and other potential confounding factors) [31]. The assessment was based on the statement from the authors of each study. This systematic review used 'yes', 'no', 'unclear' as keys of the judgments of Cochrane categories. The answer 'yes' indicated a high risk of bias, ' $U$ ' indicated an uncertain risk of bias, and a "no" indicated a low risk of bias. Studies were classified as having a low risk of bias if they had a low risk of bias for random allocation, allocation concealment, incomplete outcome data, and selective reporting.

Meta-analysis was conducted using Comprehensive metaanalysis software (version 2.2.027). Studies reporting continuous data were separately pooled from studies reporting dichotomous data. Separate meta-analyses were conducted for each included intervention specific to a particular type of urinary incontinence. Studies comparing similar interventions and controls were grouped to obtain the pooled estimate of between-group differences. For continuous data, treatment effect size and 95\% Confidence Interval (CI) were estimated. For dichotomous data, Risk Ratio (RR) and 95\% CI were calculated. The chi-square test was used to determine statistical heterogeneity. Weighted mean differences were calculated 


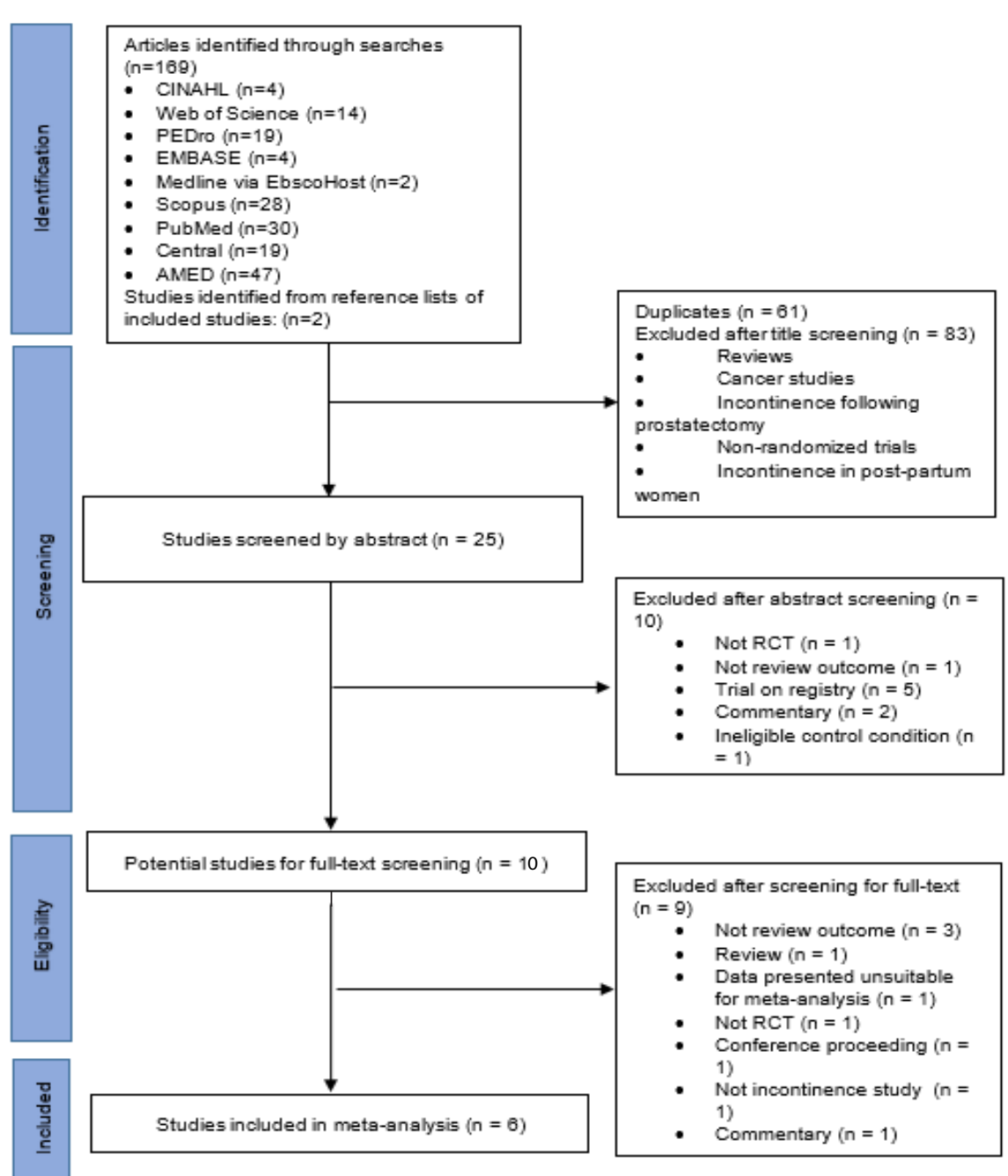

Figure 1: Flow diagram of searches and study selection.

to develop a fixed-effects model for low heterogeneity $\left(I^{2}<50 \%\right)$ or a random-effects model for high heterogeneity $\left(I^{2}>50 \%\right)$ [32]. A p-value $\leq 0.05$ was considered statistically significant.

\section{Results}

Figure 1 summarises the review process and the reasons for exclusion at each stage. Supplementary Appendix 2 summarises the studies excluded on abstract and full-text screening and the reasons for exclusion. Electronic and hand-searching yielded 168 potentially relevant articles. Among these studies, six studies met the inclusion criteria and were thus included in the review. The characteristics of each included study are summarised in Table 1. Among the six studies, we identified two studies on yoga and four on Paula exercise for Stress Urinary Incontinence (SUI) in women. Six included studies provided data for 576 participants. No studies on Tai Chi and Qigong for urinary incontinence in women were identified in the searches. Six studies on Pilates for urinary incontinence in women were identified in the searches; however, those studies were excluded during the abstract and full-text screening (please see Supplementary Appendix 2 for reasons for exclusion).
PEDro scores for included studies are reported in Table 1. Table 2 presents the summary of findings generated by the GRADEpro software. Assessment of risk of bias is summarised in Figure 2. The methodological quality based on PEDro ranged from low to high ranging from 4 to 8 , with a mean PEDro score of 5.3 out of 10. Among the six included studies, one study was of high methodological quality. The quality of studies based on the GRADE assessment tool ranged from "very low" to "low". Risk of bias assessment revealed that only one out of the six included studies was associated with a low risk of bias. All six included studies described the methods used for random sequence generation and were free from reporting bias. Two out of the six included studies reported the methods used for allocation concealment $[33,34]$. None of the included studies reported blinding of participants; however, assessors were blinded in three out of the six included studies [33-35]. The completeness of outcome data for each main outcome, including attrition and exclusions from the analysis were adequately described in one study [33]. Four out of six studies were free of any other biases [33-36].

\section{Effects of yoga on SUI}

Meta-analysis of data from two [33,37] studies of low [37] to high 
Table 1: Characteristics of included studies $(n=6)$

\begin{tabular}{|c|c|c|c|c|}
\hline $\begin{array}{l}\text { Author, year, country } \\
\text { of study and PEDro } \\
\text { scores }\end{array}$ & $\begin{array}{l}\text { Mean age of } \\
\text { participants }(y) \\
\text { sample size }\end{array}$ & Study groups and dosage of intervention and control & $\begin{array}{l}\text { Outcome } \\
\text { measure(s) }\end{array}$ & $\begin{array}{l}\text { Results: Time points of } \\
\text { assessment; Mean (SD) } \\
\text { (or) } n / N\end{array}$ \\
\hline $\begin{array}{l}\text { Liebergall- Wischnitzer } \\
\text { et al. [27], } 2005 \\
\text { Israel } \\
\text { PEDro: } 5 / 10\end{array}$ & $\begin{array}{l}\text { Age range: } 20-65^{*} \\
\text { (mean age not } \\
\text { reported) } \\
\text { Exp: } n=30 \\
\text { Con: } n=29\end{array}$ & $\begin{array}{l}\text { Exp: PE } \\
\text { Con: PFMT } \\
\text { PE: } 12 \text { weeks ( } 45 \text { min session/ week). } \\
\text { PFMT: } 4 \text { weeks ( } 30 \text {-min sessions/ week). } \\
\text { PE: Contraction and relaxation of pubococcygeal muscles, anals } \\
\text { sphincter, and eyelids. Open and close mouth and press each finger of } \\
\text { hands to thumbs. } \\
\text { PFMT: NR }\end{array}$ & $\begin{array}{l}\rightarrow \text { Pad test: } \\
\text { Urinary leakage in } \\
\text { grams }\end{array}$ & $\begin{array}{l}12 \text { weeks } \\
\text { Exp: } 5.4(8.8) \\
\text { Con: } 9.5(16.0)\end{array}$ \\
\hline $\begin{array}{l}\text { Liebergall-Wischnitzer } \\
\text { et al. [10], } 2009 \\
\text { Israel } \\
\text { PEDro: } 5 / 10\end{array}$ & $\begin{array}{l}\text { Exp: } 47.3(8.4) \\
\text { Con: } 47.9(9.3) \\
\text { EA: } n=91 \\
\text { SA: } n=86\end{array}$ & $\begin{array}{l}\text { Exp: PE } \\
\text { Con: PFMT } \\
\text { PE: } 12 \text { weeks ( } 45 \text { minutes session/ week). } \\
\text { PFMT: } 4 \text { weeks ( } 30 \text { minutes session/ week). After } 4 \text { weeks, } 2 \text { more } \\
\text { sessions } 3 \text { weeks apart. } \\
\text { PE: Contraction and relaxation of pubococcygeal muscles, anals } \\
\text { sphincter, and eyelids. Open and close mouth and press each finger of } \\
\text { hands to thumbs. } \\
\text { PFMT: Raising the vagina and anus. }\end{array}$ & $\begin{array}{l}\rightarrow \text { Pad test: } \\
\text { Urinary leakage } \\
\text { (grams) } \\
\rightarrow \text { Self-reported } \\
\text { leakage amount }\end{array}$ & $\begin{array}{l}\text { Leakage (grams); } 12 \\
\text { weeks } \\
\text { Exp: } 3.0(7.2) \\
\text { Con: } 2.8(4.3) \\
\text { Leakage amount; } 12 \\
\text { weeks } \\
\text { Exp: } 74 / 91 \\
\text { Con: } 39 / 86\end{array}$ \\
\hline $\begin{array}{l}\text { Liebergall-Wischnitzer } \\
\text { et al. [35], } 2012 \\
\text { Israel } \\
\text { PEDro: } 5 / 10\end{array}$ & $\begin{array}{l}\text { Exp: } 46.7(8.0) \\
\text { Con: } 46.6(8.9) \\
\text { Exp: } n=65 \\
\text { Con: } n=59\end{array}$ & $\begin{array}{l}\text { Exp: PE } \\
\text { Con: PFMT } \\
\text { PE: } 12 \text { weeks ( } 45 \text { minutes session/ week). } \\
\text { PFMT: Once a week for } 4 \text { weeks. After } 4 \text { weeks, } 2 \text { more sessions } 3 \\
\text { weeks apart for a total of } 6 \text { sessions over } 12 \text { weeks } \\
\text { PE: Contraction and relaxation of the eyelids; raising the upper lip } \\
\text { to the nose as the nose is lowered to the upper lip; contraction and } \\
\text { relaxation of the levator any muscles alone or in conjunction with a "sh" } \\
\text { sound. } \\
\text { PFMT: Raising the vagina from the chair (levator any) in sitting. 10s } \\
\text { rest between Contractions. Each contraction performed 1-2 minutes } \\
\text { apart. }\end{array}$ & $\begin{array}{l}\rightarrow \text { Urinary leakage } \\
\text { in grams } \\
\rightarrow \text { Self-reported } \\
\text { leakage amount }\end{array}$ & $\begin{array}{l}\text { Leakage (grams); } 12 \\
\text { weeks } \\
\text { Exp: } 2.9 \text { (7.1) } \\
\text { Con: } 2.4 \text { (4.4) } \\
\text { Leakage amount; } 12 \\
\text { weeks } \\
\text { Exp: } 31 / 65 \\
\text { Con: } 28 / 59\end{array}$ \\
\hline $\begin{array}{l}\text { Liebergall-Wischnitzer } \\
\text { et al. [38], } 2013 \text { Israel } \\
\text { PEDro: 4/10 }\end{array}$ & $\begin{array}{l}\text { Exp: } 48.5(7.6) \\
\text { Con: } 47.8(8.6) \\
\text { Exp: } n=64 \\
\text { Con: } n=78\end{array}$ & $\begin{array}{l}\text { Exp: PE } \\
\text { Con : PFMT } \\
\text { PE: } 12 \text { weeks ( } 45 \text { min session/ week). } \\
\text { PFMT: } 4 \text { weeks ( } 30 \text { min session/ week). After } 4 \text { weeks, } 2 \text { more } \\
\text { sessions } 3 \text { weeks apart for a total of } 6 \text { sessions over } 12 \text { weeks. } \\
\text { PE: Opening and closing the mouth (and feeling the contraction in the } \\
\text { face, PFMs and anus) and palms (and feeling the contraction in the } \\
\text { shoulders and PFMs). } \\
\text { PFMT: Raising the vagina from the chair (levator any) in sitting. 10s } \\
\text { rest between contractions. Each contraction performed 1-2 minutes } \\
\text { apart. }\end{array}$ & $\begin{array}{l}\rightarrow \text { Self-reported } \\
\text { leakage amount }\end{array}$ & $\begin{array}{l}12 \text { weeks } \\
\text { Exp: } 49 / 64 \\
\text { Con: } 55 / 79\end{array}$ \\
\hline $\begin{array}{l}\text { Huang et al. [37], } 2014 \\
\text { USA } \\
\text { PEDro: } 5 / 10\end{array}$ & $\begin{array}{l}\text { Exp: } 60.5(8.4) \\
\text { Con: } 62.4(8.3) \\
\text { Exp: } n=9 \\
\text { Con: } n=9\end{array}$ & $\begin{array}{l}\text { Exp: Yoga (group-based) } \\
\text { Con: Wait-list } \\
\text { Yoga: } 6 \text { weeks (supervised, } 90 \text { minutes/ session, twice weekly) } \\
\text { Con: Yoga classes at a local yoga studio. } \\
\text { Yoga: Hatha yoga program consisting of } 8 \text { yoga postures. } \\
\text { Con: } \$ 180 \text { gift certificate for yoga classes at a local yoga } \\
\text { Studio. }\end{array}$ & $\begin{array}{l}\rightarrow \text { Number of } \\
\text { incontinence } \\
\text { episodes }\end{array}$ & $\begin{array}{l}6 \text { weeks } \\
\text { Exp: } 0.71(0.8) \\
\text { Con: } 0.21(1.1)\end{array}$ \\
\hline
\end{tabular}




\begin{tabular}{|c|c|c|c|c|}
\hline $\begin{array}{l}\text { Huang et al. [33], } 2019 \\
\text { USA } \\
\text { PEDro: } 8 / 10\end{array}$ & $\begin{array}{l}\text { Exp: } 65.5(9.1) \\
\text { Con: } 66.6(6.8) \\
\text { Exp: } n=28 \\
\text { Con: } n=28\end{array}$ & $\begin{array}{l}\text { Exp: Yoga (group-based) } \\
\text { Con: Attention } \\
12 \text { weeks (supervised, } 90 \text { minutes/ session, twice weekly) } \\
\text { Yoga: Hatha yoga program consisting of } 15 \text { yoga postures. } \\
\text { Con: Non-specific stretching and strengthening exercises. }\end{array}$ & $\begin{array}{l}\rightarrow \text { Number of } \\
\text { incontinence } \\
\text { episodes }\end{array}$ & $\begin{array}{l}12 \text { weeks (change } \\
\text { scores) } \\
\text { Exp: } 0.8 \\
\text { Con: } 0.4\end{array}$ \\
\hline
\end{tabular}

Note: Con: Control group; Exp: Experimental group; NR: Not Reported; PE: Paula Exercise; PFM: Pelvic Floor Muscle; PFMT: Pelvic Floor Muscle Training. 'Age reported as mean and SD unless specified.

Table 2: Summary of findings (GRADE) for the effectiveness of interventions compared to control.

\begin{tabular}{|c|c|c|c|c|c|}
\hline \multicolumn{6}{|c|}{ SUI: Paula exercise compared to PFMT } \\
\hline \multirow{2}{*}{ Outcomes } & \multicolumn{2}{|r|}{ Illustrative comparative risks* $(95 \% \mathrm{Cl})$} & \multirow{2}{*}{$\begin{array}{l}\text { Relative } \\
\text { effect } \\
(95 \% \mathrm{Cl})\end{array}$} & \multirow{2}{*}{$\begin{array}{l}\text { No of Participants } \\
\text { (studies) }\end{array}$} & \multirow{2}{*}{$\begin{array}{l}\text { Quality of the } \\
\text { evidence } \\
\text { (Grade) }\end{array}$} \\
\hline & $\begin{array}{l}\text { Assumed } \\
\text { risk }\end{array}$ & Corresponding risk & & & \\
\hline $\begin{array}{l}\text { Amount of urine leak in } \\
\text { grams }\end{array}$ & & $\begin{array}{c}\text { The mean pad test leaks in the intervention groups was } 0.47 \\
\text { higher ( } 1.79 \text { lower to } 0.84 \text { higher) }\end{array}$ & & $\begin{array}{l}360 \text { (3 studies) } \\
{[10,11,27]}\end{array}$ & $\begin{array}{c}\oplus \Theta \Theta \Theta \\
\text { very low }\end{array}$ \\
\hline \multicolumn{6}{|c|}{ SUI: Paula exercise compared to PFMT } \\
\hline Outcomes & $\begin{array}{l}\text { Assumed } \\
\text { risk }\end{array}$ & Corresponding risk & $\begin{array}{l}\text { Relative } \\
\text { effect } \\
(95 \% \mathrm{CI})\end{array}$ & $\begin{array}{l}\text { No of Participants } \\
\text { (studies) }\end{array}$ & $\begin{array}{l}\text { Quality of the } \\
\text { evidence } \\
\text { (Grade) }\end{array}$ \\
\hline \multirow{4}{*}{$\begin{array}{l}\text { Number of women reporting } \\
\text { small leaks }\end{array}$} & & Study population & \multirow{4}{*}{$\begin{array}{l}\text { RR } 1.26 \\
(0.88 \text { to } \\
1.80)\end{array}$} & \multirow{4}{*}{$\begin{array}{c}443 \\
\text { (3 studies) }[10,11,28]\end{array}$} & \multirow{4}{*}{$\begin{array}{c}\oplus \ominus \ominus \ominus \\
\text { very low } \mathbf{l}^{\mathrm{b}, \mathrm{c}}\end{array}$} \\
\hline & $\begin{array}{c}545 \text { per } \\
1000\end{array}$ & $\begin{array}{c}692 \text { per } 1000 \\
(485 \text { to } 986)\end{array}$ & & & \\
\hline & \multicolumn{2}{|r|}{ Moderate } & & & \\
\hline & $\begin{array}{c}475 \text { per } \\
1000\end{array}$ & $\begin{array}{l}603 \text { per } 1000 \\
(423 \text { to } 860)\end{array}$ & & & \\
\hline \multicolumn{6}{|c|}{ SUI: Yoga compared to control } \\
\hline \multirow{3}{*}{ Outcomes } & & Illustrative comparative risks* $(95 \% \mathrm{Cl})$ & \multirow{2}{*}{$\begin{array}{l}\text { Relative } \\
\text { effect } \\
(95 \% \mathrm{Cl})\end{array}$} & \multirow{2}{*}{$\begin{array}{l}\text { No of Participants } \\
\text { (studies) }\end{array}$} & \multirow{2}{*}{$\begin{array}{l}\text { Quality of the } \\
\text { evidence } \\
\text { (Grade) }\end{array}$} \\
\hline & $\begin{array}{l}\text { Assumed } \\
\text { risk }\end{array}$ & Corresponding risk & & & \\
\hline & Control & Intervention & & & \\
\hline $\begin{array}{l}\text { Number of incontinence } \\
\text { episodes }\end{array}$ & & $\begin{array}{l}\text { The mean frequency of incontinence episodes in the } \\
\text { intervention groups was } \mathbf{0 . 8 3} \text { lower } \\
\text { ( } 1.64 \text { to } 0.02 \text { lower) }\end{array}$ & & $\begin{array}{c}74 \\
\text { (2 studies) }[33,37]\end{array}$ & 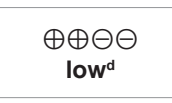 \\
\hline
\end{tabular}

Note: Cl: Confidence interval; PFMT: Pelvic Floor Muscle Training; RR: Risk ratio; ${ }^{\star}$ The basis for the assumed risk (e.g. the median control group risk across studies) is provided in footnotes. The corresponding risk (and its $95 \%$ confidence interval) is based on the assumed risk in the comparison group and the relative effect of the intervention (and its $95 \% \mathrm{Cl}$ ).

Grade Working Group grades of evidence.

High quality: Further research is very unlikely to change our confidence in the estimate of effect.

Moderate quality: Further research is likely to have an important impact on our confidence in the estimate of effect and may change the estimate.

Low quality: Further research is very likely to have an important impact on our confidence in the estimate of effect and is likely to change the estimate.

Very low quality: We are very uncertain about the estimate.

a Lack of concealed allocation in two studies (Libergall-Wischnitzer 2012 and Libergall-Wischnitzer 2005), lack of assessor blinding in one study (Libergall-Wischnitzer 2005), $>15 \%$ dropout in two studies (Libergall-Wischnitzer 2012 and Libergall-Wischnitzer 2009), and lack of intention-to-treat analysis in three studies (LibergallWischnitzer 2012, Libergall-Wischnitzer 2009, and Libergall-Wischnitzer 2005).

bide $\mathrm{Cl}$.

'Lack of concealed allocation in two studies (Libergall-Wischnitzer 2012 and Libergall-Wischnitzer 2013), lack of assessor blinding in one study (Libergall-Wischnitzer 2013) and $>15 \%$ dropout, lack of intention-to-treat analysis in three studies (Libergall-Wischnitzer 2012, Libergall-Wischnitzer 2013, and Libergall-Wischnitzer 2009).

${ }^{\mathrm{d} A l l o c a t i o n}$ concealment, assessor blinding and intention-to-treat analysis not done in one study (Huang 2014).

[33] methodological quality, low-grade evidence involving 74 women with SUI revealed a statistically significant decrease in the number of incontinence episodes in the yoga group compared to women in the control group (MD 0.83 [95\% CI - 1.64 to 0.02]; $\mathrm{p}=0.04$; Figure 3) during the 6-12week follow-up period.

\section{Effects of Paula exercise on SUI}

Meta-analysis of data from three [34-36] methodologically low-quality, very low-grade studies involving 360 women with SUI demonstrated no significant difference between groups receiving Paula exercise and PFMT on grams of urine lost (1h pad test) in women with SUI (MD 0.47 [95\% CI - 1.79 to 0.84] p=0.48; Figure 4) during the 12-week follow-up period. Meta-analysis of data from three $[34,35,38]$ methodologically low-quality, very low-grade studies involving 443 women with SUI also found no significant difference between groups receiving Paula exercise and PFMT in the number of women reporting small leaks (RR 1.26 [95\% CI - 0.88 to 1.80$] \mathrm{p}=0.19$; Figure 5) during the 12-week follow-up period.

\section{Discussion}

The efficacy of mind-body therapies, including Pilates, Paula exercise, Qigong, Tai Chi, and yoga compared to control for the management of urinary incontinence in women, was evaluated in this review.

Meta-analysis of the two $[33,37]$ trials of yoga revealed a 


\begin{tabular}{|c|c|c|c|c|c|c|c|}
\hline & 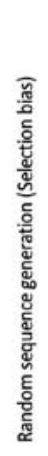 & 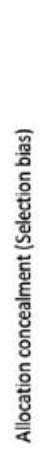 & 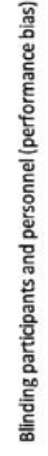 & 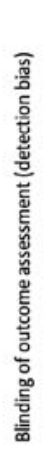 & 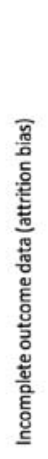 & 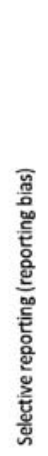 & 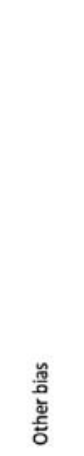 \\
\hline Huang 2014 & No & Yes & Yes & Yes & Yes & No & Unclear \\
\hline Huang 2019 & No & No & Yes & No & No & No & No \\
\hline Liebergall-Wischnitzer 2005 & No & Yes & Yes & Yes & Yes & No & No \\
\hline Liebergall-Wischnitzer 2009 & No & No & Yes & No & Yes & No & No \\
\hline Liebergall-Wischnitzer 2012 & No & Yes & Yes & No & Yes & No & No \\
\hline Liebergall-Wischnitzer 2013 & No & Yes & Yes & Yes & Yes & No & Unclear \\
\hline
\end{tabular}

Figure 2: Risk of bias of each included study.

statistically significant decrease in the number of incontinence episodes in women with SUI. This result was derived from two studies of low [37] to high [33] methodological quality, low-grade evidence. Both the studies utilized Hatha yoga postures that include active postures to engage the PFMs [33]. The Hatha yoga postures are believed to increase the awareness and control of the PFMs, reduce stress and anxiety, and improve general fitness and condition [33,37]. The two studies [33,37] assessed a set of 1534 and eight [37] yoga postures executed in 90-minute group sessions, twice weekly for 12 and six weeks, respectively. The Hatha yoga poses common to both studies include the Tadasana (mountain pose), Utkatasana (chair pose), Trikonasana (triangle pose), Malasana (squat pose), Viparita
Karani Variation (legs up the wall pose), Salamba Set Bandhasana (supported bridge pose), Supta Baddha Konasana (reclined cobbler's pose), and Savasana (corpse pose) [33,37]. Although the effects of yoga were statistically significant, the evidence was from two small studies associated with low [37] to high [33] risk of bias. However, considering the low risks of yoga, this intervention may be considered for clinical use.

The pooled analysis of studies $(n=503)$ of low methodological and very low-grade quality revealed no superior benefits of Paula exercise compared to PFMT for the treatment of SUI in women. Paula exercise works on the principle that all sphincters in the body work in a synchronized manner [34,35]; therefore, exercising the circular muscles of the mouth, eyes or nose may result in PFMs cocontractions $[12,15]$. However, a scientific premise for contracting the circular muscles of the face to facilitate PFMs co-contraction is lacking. Experimental studies that examined the influence of the Paula exercise on PFMs using electromyography and 4-D ultrasound in healthy nulliparous [16] (without pelvic floor muscle dysfunction), pregnant and postpartum [17] women observed no change in bioelectric activity, length of PFMs, or levator hiatus constriction during Paula exercise. Although studies have evaluated the effect of Paula exercise on pelvic floor muscle activity in nulliparous, pregnant, and postpartum women, results may not be generalized to women with incontinence because pelvic floor muscle function and strength is related to continence status [39]. Further research to investigate the influence of Paula exercise on pelvic floor muscle function in women with incontinence is required to form a scientific premise for the theoretical proposition that all sphincters in the body work simultaneously and can affect one another $[16,17]$.

Tai Chi has been found to be beneficial for the treatment of lower urinary tract symptoms in men [40], but the effectiveness of Tai Chi for the treatment of urinary incontinence in women is not known.

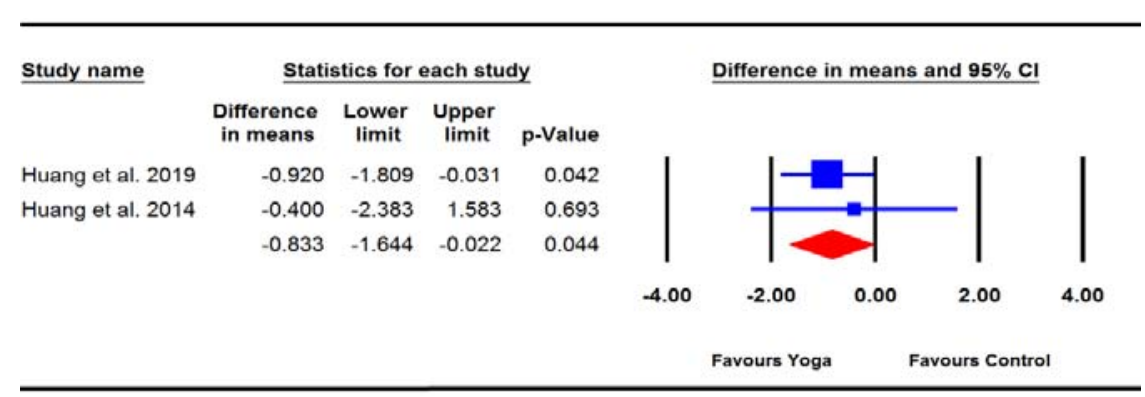

Figure 3: Yoga vs. control for number of incontinence episodes in women with stress urinary incontinence at 6-12 weeks follow-up.

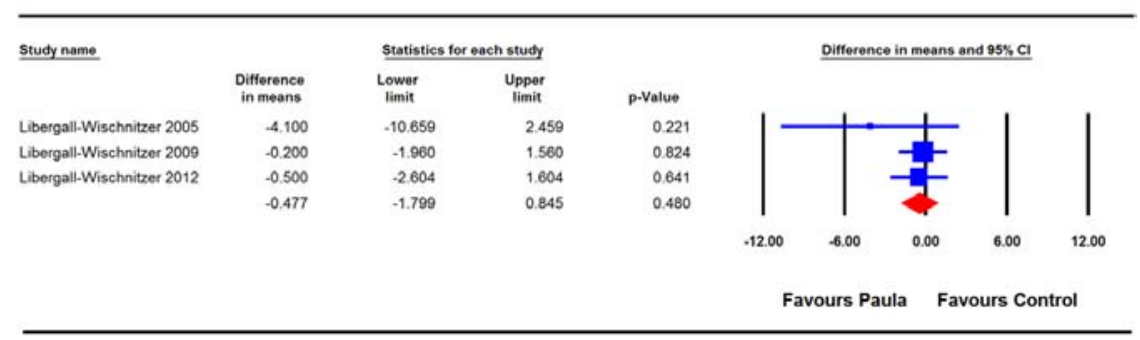

Figure 4: Paula exercise vs. PFMT for urine leak in grams in women with stress urinary incontinence at 12 weeks follow-up. Note: PFMT: Pelvic Floor Muscle Training. 


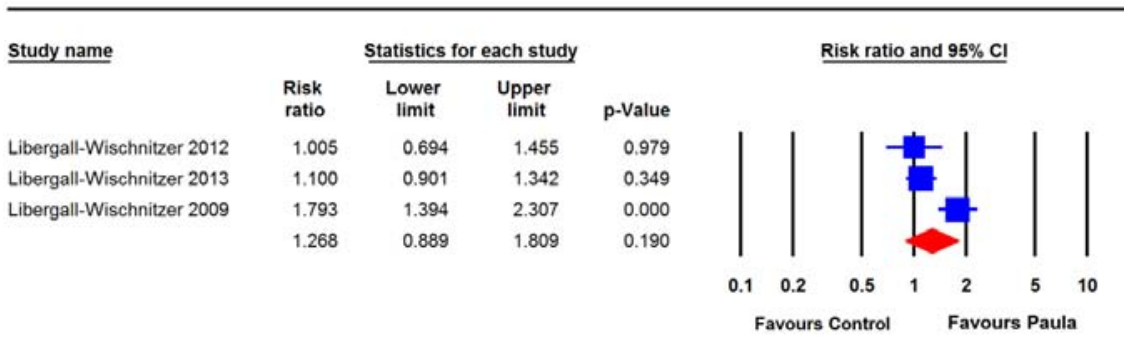

Figure 5: Paula exercise vs. PFMT for number of small leaks in women with stress urinary incontinence at 12 weeks follow-up. Note: PFMT: Pelvic Floor Muscle Training.

Qigong is proposed to improve urinary incontinence by regulating qi [14,41]; however, no studies examine the effectiveness of Qigong for the treatment of urinary incontinence in women. No studies on Tai Chi and Qigong for urinary incontinence in women were identified in the searches. Future well-conducted trials to evaluate the effects of interventions that have received less or no attention, such as Qigong and Tai Chi, are recommended.

\section{Strengths and Weaknesses}

An extensive and sensitive search strategy was used to identify RCTs investigating the effect of mind-body therapies for urinary incontinence in women. The other strengths are the use of quality assessment tools that are psychometrically valid, and the inclusion of unpublished works that may present insignificant results. This review had some potential weaknesses. Only studies published in English, Chinese and Cantonese were included in the review. Despite the potential for language bias, no studies other than English were identified in the searches. Five of the six included studies were of low methodological quality and associated with a high risk of bias; and grade quality of the included studies was low to very low. The number of included studies is small, and only a few studies were included in each meta-analysis.

\section{Conclusions and Implications for Future Research}

This systematic review found yoga to be beneficial for the treatment of SUI in women. However, these results must be considered with caution because meta-analysis was conducted using two small studies of low-high methodological quality, low-grade evidence. Also, one of the two studies was associated with a high risk of bias. The pooled analysis of methodologically low quality, very low-grade studies revealed no superior benefits of Paula exercise compared with PFMT for the treatment of SUI. Well-conducted adequately powered trials to evaluate the effectiveness of yoga for urinary incontinence are recommended to understand the positive results from smaller trials. Future adequately powered, high-quality research on other mindbody interventions, such as Pilates, Qigong, and Tai Chi, which have currently received little attention, is also warranted.

Financial support: This work is supported by the start-up fund (1-ZE8G) for early-career academics by the Hong Kong Polytechnic University.

\section{Acknowledgment}

The authors would like to thank Mr. Bello Umar Muhammad and
Joe Wing Pun for their assistance with comprehensive meta-analysis and risk of bias assessment, respectively.

\section{Review Registration}

This systematic review is registered in the PROSPERO registry (CRD42019135036).

\section{References}

1. Wolsko PM, Eisenberg DM, Davis RB, Phillips RS. Use of mind-body medical therapies. Journal of general internal medicine. 2004; 19: 43-50.

2. Astin JA, Shapiro SL, Eisenberg DM, Forys KL. Mind-body medicine: state of the science, implications for practice. The Journal of the American Board of Family Practice. 2003; 16: 131-147.

3. Wieland LS, Shrestha N, Lassi ZS, Panda S, Chiaramonte D, Skoetz N. Yoga for treating urinary incontinence in women. The Cochrane database of systematic reviews. 2019; 2: Cd012668.

4. Tenfelde S, Logan R, Abernethy M. Yoga for the Pelvic Floor. Beginnings. 2014; 34: 24-26.

5. Wieland LS, Shrestha N, Lassi ZS, Panda S, Chiaramonte D, Skoetz N. Yoga for treating urinary incontinence in women. The Cochrane database of systematic reviews. 2019; 2: Cd012668.

6. Vempati R, Bijlani RL, Deepak KK. The efficacy of a comprehensive lifestyle modification programme based on yoga in the management of bronchial asthma: a randomized controlled trial. BMC pulmonary medicine. 2009; 9: 37.

7. Hagins M, Selfe T, Innes K. Effectiveness of yoga for hypertension: systematic review and meta-analysis. Evidence-Based Complementary and Alternative Medicine. 2013; 2013: 649836.

8. Cramer $\mathrm{H}$, Lauche $\mathrm{R}$, Haller $\mathrm{H}$, Dobos $\mathrm{G}$. A systematic review and metaanalysis of yoga for low back pain. The Clinical journal of pain. 2013; 29 : 450-460.

9. Haaz S, Bartlett SJ. Yoga for arthritis: a scoping review. Rheumatic Disease Clinics. 2011; 37: 33-46.

10. Mooventhan A, Nivethitha L. Evidence based effects of yoga in neurologica disorders. Journal of Clinical Neuroscience. 2017; 43: 61-67.

11. Cramer H, Lauche R, Klose P, Lange S, Langhorst J, Dobos GJ. Yoga for improving health-related quality of life, mental health and cancer-related symptoms in women diagnosed with breast cancer. Cochrane Database of Systematic Reviews. 2017; 1: CD010802.

12. Bø K, Herbert RD. There is not yet strong evidence that exercise regimens other than pelvic floor muscle training can reduce stress urinary incontinence in women: A systematic review. Journal of Physiotherapy. 2013; 59: 159-168.

13. Wang Y, Zhishun L, Peng W, Zhao J, Liu B. Acupuncture for stress urinary incontinence in adults. Cochrane Database of Systematic Reviews. 2013.

14. Isahak AF. Qigong and the kidneys. 2003.

15. McClurg D, Pollock A, Campbell P, Hazelton C, Elders A, Hagen S, et al. 
Conservative interventions for urinary incontinence in women: an Overview of Cochrane systematic reviews. Cochrane Database of Systematic Reviews. 2016; 2016: CD012337.

16. Resende APM, Zanetti MR, Petricelli CD, Castro RA, Alexandre SM Nakamura MU. Effects of the Paula method in electromyographic activation of the pelvic floor: a comparative study. International Urogynecology journal. 2011; 22: 677-680.

17. Bø K, Hilde G, Stær-Jensen J, Brækken IH. Can the Paula method facilitate co-contraction of the pelvic floor muscles? A 4D ultrasound study International Urogynecology journal. 2011; 22: 671-676.

18. Herderschee R, Hay-Smith EJC, Herbison GP, Roovers JP, Heineman MJ Feedback or biofeedback to augment pelvic floor muscle training for urinary incontinence in women. Cochrane Database of Systematic Reviews. 2011 CD009252.

19. Hošnjak AM, Ledinski Fičko S, Smrekar M, llić B, Kolačko Š, Jurić M. Effectiveness of Biofeedback Therapy as Conservative Choice for Management of Female Stress Urinary Incontinence. 2017; 1: 103-114.

20. Berghmans L, Hendriks H, De Bie R, Van Waalwijk E, Doorn V, Bø K, et al Conservative treatment of urge urinary incontinence in women: a systematic review of randomized clinical trials. BJU international. 2000; 85: 254-263.

21. Teunissen T, Jonge Ad, Weel Cv, Lagro-Janssen A. Treating urinary incontinence in the elderly--conservative therapies that work: a systematic review. 2004.

22. Maher CG, Sherrington C, Herbert RD, Moseley AM, Elkins M. Reliability of the PEDro scale for rating quality of randomized controlled trials. Physical therapy. 2003; 83: 713-721.

23. Guyatt G, Oxman AD, Akl EA, Kunz R, Vist G, Brozek J, et al. GRADE guidelines: 1. Introduction-GRADE evidence profiles and summary of findings tables. Journal of clinical epidemiology. 2011; 64: 383-394.

24. Maher CG. A systematic review of workplace interventions to prevent low back pain. Australian Journal of Physiotherapy. 2000; 46: 259-269.

25. Guyatt GH, Oxman AD, Vist GE, Kunz R, Falck-Ytter Y, Alonso-Coello P, et al GRADE: an emerging consensus on rating quality of evidence and strength of recommendations. BMJ (Clinical research ed). 2008; 336: 924-926.

26. Guyatt GH, Oxman AD, Vist G, Kunz R, Brozek J, Alonso-Coello P, et al. GRADE guidelines: 4. Rating the quality of evidence-study limitations (risk of bias). Journal of clinical epidemiology. 2011; 64: 407-415

27. Guyatt GH, Oxman AD, Kunz R, Woodcock J, Brozek J, Helfand M, et al. GRADE guidelines: 8. Rating the quality of evidence-indirectness. Journal of clinical epidemiology. 2011; 64: 1303-1310.

28. Guyatt GH, Oxman AD, Kunz R, Brozek J, Alonso-Coello P, Rind D, et al. GRADE guidelines 6 . Rating the quality of evidence-imprecision. Journal of clinical epidemiology. 2011; 64: 1283-1293.

29. Guyatt GH, Oxman AD, Kunz R, Woodcock J, Brozek J, Helfand M, et al. GRADE guidelines: 7. Rating the quality of evidence-inconsistency. Journal of clinical epidemiology. 2011; 64: 1294-1302.
30. Guyatt GH, Oxman AD, Montori V, Vist G, Kunz R, Brozek J, et al. GRADE guidelines: 5. Rating the quality of evidence-publication bias. Journal of clinical epidemiology. 2011; 64: 1277-1282.

31. Higgins J, Altman D, Sterne J. Assessing risk of bias in included studies Cochrane handbook for systematic reviews of interventions. Cochrane book series. 2008: 187-241.

32. Borenstein M, Hedges LV, Higgins JP, Rothstein HR. A basic introduction to fixed-effect and random-effects models for meta-analysis. Research synthesis methods. 2010; 1: 97-111

33. Huang AJ, Chesney M, Lisha N, Vittinghoff E, Schembri M, Pawlowsky S, et al. A group-based yoga program for urinary incontinence in ambulatory women: feasibility, tolerability, and change in incontinence frequency over 3 month in a single-center randomized trial. American journal of obstetrics and gynecology. 2019; 220: 87. e1-e13.

34. Liebergall-Wischnitzer M, H-C D, Lavy Y, Manor O, Shveiky D, Paltiel O. Randomized trial of circular muscle versus pelvic floor training for stress urinary incontinence in women. Journal of Women's Health. 2009; 18: 377 385.

35. Liebergall-Wischnitzer M, Paltiel O, Hochner Celnikier D, Lavy Y, Manor O, Woloski Wruble AC. Sexual function and quality of life of women with stress urinary incontinence: a randomized controlled trial comparing the Paula method (circular muscle exercises) to Pelvic Floor Muscle Training (PFMT) exercises. Journal of sexual medicine. 2012; 9: 1613-1623.

36. Liebergall-Wischnitzer M, H-C D, Lavy Y, Manor O, Arbel R, Paltiel O. International Urogynecology Journal. Paula method of circular muscle exercises for urinary stress incontinence-a clinical trial. 2005; 16: 345-351.

37. Huang AJ, Jenny HE, Chesney MA, Schembri M, Subak LL. A groupbased yoga therapy intervention for urinary incontinence in women: a pilot randomized trial. Female pelvic medicine \& reconstructive surgery. 2014; 20 : 147-154.

38. Liebergall-Wischnitzer M, Paltiel O, Lavy Y, Shveiky D, Manor O, HochnerCelnikier D. Long-term efficacy of Paula method as compared with pelvic floor muscle training for stress urinary incontinence in women: a 6-month followup. Journal of wound, ostomy, and continence nursing: official publication of the wound, ostomy and continence nurses society. 2013; 40: 90-96.

39. Mørkved S, Salvesen KÅ, Bø K, Eik-Nes S. Pelvic floor muscle strength and thickness in continent and incontinent nulliparous pregnant women. International Urogynecology Journal. 2004; 15: 384-390.

40. Jung S, Lee EN, Lee SR, Kim MS, Lee MS. Tai Chi for lower urinary tract symptoms and quality of life in elderly patients with benign prostate hypertrophy: a randomized controlled trial. Evidence-Based Complementary and Alternative Medicine 2012; 2012: 624692.

41. Gallagher B. Tai chi chuan and qigong: Physical and mental practice for functional mobility. Topics in Geriatric Rehabilitation. 2003; 19: 172-182. 